\title{
Biological functions and health promoting effects of brown seaweeds in swine nutrition
}

\begin{abstract}
Marine macroalgae could be an important supplement in animal nutrition for their health-promoting effects. In recent years, the search of natural substances as substitutes of prophylactic antibiotics increased. Seaweeds, in particular brown algae, possess distinctive compounds such as laminarin and fucoidan, studied for their biologically active functions. Recent studies have shown that these bioactive components can positively affect the health and wellbeing improving intestinal mucosa metabolism, and have anti-microbial, anti-inflammatory and immunomodulatory effects. The present work is focuses on the health-promoting activities of seaweeds, in particular brown algae, as swine dietary supplement.
\end{abstract}

Keywords: brown seaweed, health, swine, dietary supplementation
Volume I Issue I - 2014

\author{
Federica Maghin, Sabrina Ratti, Carlo Corino \\ Department of Health,Animal Science and Food Safety, \\ University of Milan, Europe
}

\begin{abstract}
Correspondence: Federica Maghin, Department of Health, Animal Science and Food Safety, University of Milan, via Trentacoste 2, Milan 20100, Europe, Tel 39025031 5728, Emailmaghin@unimi.it
\end{abstract}

Received: July 23, 2014 | Published: August 04, 2014

\section{Introduction}

Recently, prophylactic use of antibiotics in livestock have been banned by European Community with the consequence of a growing research towards new, safe and natural ingredients, like plant extract, that would have antimicrobial properties. ${ }^{1}$ In this context, seaweed extracts have assumed great importance in animal nutritionfor the high content in bioactive molecules. ${ }^{2}$ Seaweed or marine macroalgae are divided in three categories: red (Rhodophyta), brown (Phaeophyta) and green (Chlorophyta). ${ }^{3}$

The seaweeds have shown interest as functional dietary ingredient due to its several health benefits related to their content of sulfated polysaccharides, phlorotannins, diterpenes, omega-3 PUFAs, minerals and vitamins. ${ }^{4,5}$ In particular brown macroalgae have the higher content of water solubles polysaccharides, laminarin and fucoidan, compared to red and green seaweeds ${ }^{6}$ which contain phenol component with higher free-radical scavenging properties. ${ }^{3}$

The following biologically active functions of brown seaweeds are discussed in the present study: prebiotic function such as antimicrobial activity and improvement of digestibility; antioxidant, antiinflammatory, and immunomodulatory activities.

\section{Prebiotic function}

\section{Anti-microbial activity}

Seaweeds are rich in sulfated polysaccharides in particular laminarin and fucoidan, that can act as prebiotics with positive effect on gut health. ${ }^{7,8}$ These compounds are effective against Gram positive bacteria, ${ }^{9,10}$ and Gram negative such as Escherichia coli. ${ }^{11}$ Laminarin consists mainly of $\beta$-glucans that reveal prebiotic function, increasing Bifidobacteria and Lactobacilli species in the large intestine. ${ }^{12}$ Gut health is indirectly modulated by laminarin, with the microbial production of short-chain fatty acids (SCFA), in particular butyrate. ${ }^{13-14}$ This SCFA is well known to be the main energy source for intestinal cells, stimulating cell growth. ${ }^{15}$ Moreover, fucoidans are also studied for their antibacterial properties. ${ }^{16}$

Recent study $^{17}$ showed that dietary supplementation with laminarin $(300 \mathrm{mg} / \mathrm{kg})$ and fucoidan $(236 \mathrm{mg} / \mathrm{kg})$, independently or in combination, for 21 days increased daily gain in weaned piglets. In particular, authors found that laminarin was able to reduce in Escherichiacoli population.

Similarly, Reilly et al. ${ }^{18}$ found that dietary supplementation with laminarin $(1.5 \mathrm{~g} / \mathrm{kg})$ had a positive effect on the bacteria population Lactobacilli, Enterobacteria and Bifidobacteria, in weaned pigs. Moreover, recently seaweed has been considered as a dietary supplementation in piglets, modulating at weaning the negative changes in gut morphology and microbial populations. ${ }^{19}$

\section{Influence on digestibility}

McAlpine et al. ${ }^{20}$ have highlighted the effect of the seaweed extract on diet digestibility. The authors found that inclusion of laminarin $(300 \mathrm{mg} / \mathrm{kg})$ and fucoidan $(240 \mathrm{mg} / \mathrm{kg})$ in weaned piglets increased the coefficient of apparent total tract digestibility (CTTAD). The piglets fed with seaweed extract had a higher CTTAD of nitrogen, dry matter, and non-digestible fiber or NDF compared with pigs fed by basal diet. Also Gahan et al. ${ }^{21}$ showed that laminarin and fucoidan mixture in piglet diet $(4 \mathrm{~g} / \mathrm{kg}$ feed) could replace lactose dietary supplementation $(60 \mathrm{~g} / \mathrm{kg})$ without adversely affecting growth rate and feed efficiency in antibiotic free diet. Another study ${ }^{22}$ reveals that the dietary supplementation with laminarin $(300 \mathrm{mg} / \mathrm{kg}$ feed) has a positive effect on diet digestibility, enhancing growth performance in pig.

\section{Antioxidant function}

Brown algae have antioxidant properties due to the presence of phenols, flavonoids, tannins, and phlorotannins..$^{23}$ O'Sullivan et al..$^{24}$ studied in vitro antioxidant effects in five different brown algae. They found that two brown algae, Pelvetiacanaliculata and Fucus serratus, prevent $\mathrm{H}_{2} \mathrm{O}_{2}$-mediated superoxide dismutase (SOD) depletion and ensurea DNA protective effects. In another study Zhang et al. ${ }^{25}$ reported that dietary supplementation with Porphyra in mice $(200 \mathrm{mg} /$ $\mathrm{kg}$ feed) reduce the risk of lipid peroxidation in the aging process. In contrast, a recent study reported that the dietary inclusion of different levels of seaweed extract (from $2.5 \mathrm{~g} / \mathrm{kg}$ to $10 \mathrm{~g} / \mathrm{kg}$ feed) did not enhance plasma oxidative status. ${ }^{26}$ 


\section{Anti-inflammatory}

Brown macroalgae showed also anti-inflammatory effects. ${ }^{27}$ In fact, a lower expression of pro-inflammatory cytokines in the colon was observed in piglets after laminarin dietary supplementation. ${ }^{28}$ Moreover, laminarin dietary supplementation $(600 \mathrm{mg} / \mathrm{kg})$ significantly increased gut mucins gene expression (MUC 2 and 4), with a protective effects on epithelial cells. ${ }^{29}$ The ex vivo antiinflammatory response of extracts of brown seaweed on swine colon was also evaluated. Colon samples were homogenized and mixed with $10 \mu \mathrm{g} / \mathrm{ml}$ of bacterial lipopolysaccharides by Escherichia coli to induce a pro-inflammatory responsein relation to seaweed extract inclusion $(1 \mathrm{mg} / \mathrm{ml})$. The results demonstrated that extract of brown algae had anti-inflammatory activity reducing the pro-inflammatory cytokine response. ${ }^{2}$

\section{Immunomodulatory}

Laminarin over that antimicrobial has also immunomodulatory function. ${ }^{30}$ In a recent trial Leonard et al. ${ }^{31}$ studied the effect of seaweed extract $(1.8 \mathrm{~g} /$ day) in the diet of pregnant sows. They found an increase of immunoglobulin $\mathrm{G}(\mathrm{IgG})$ in the colostrum of sows fed with seaweed and consequently an increase of serum IgG in piglets. Also Katayama et al. ${ }^{32}$ observed that dietary supplementation with $0.8 \%$ of seaweed extract increased immunoglobulin A and $\mathrm{G}$, enhancing the immune system in pigs.

\section{Conclusion}

The biological activities of brown seaweeds could be used to improve health and welfare of pig. The prebiotic effect and the antimicrobial activity of laminarin and fucoidan may are beneficial for the preventive treatment of gastrointestinal diseases and to enhance diet digestibility in the post-weaning piglet. Moreover, laminarin exerts an anti-inflammatory activity, reducing the pro-inflammatory cytokine response. The brown seaweed dietary supplementation might positively affect immune system, enhancing immunoglobulin production. In conclusion the bioactive components in seaweed extract, revealed beneficial effects and can be used as dietary supplement in pig to sustain the production, enhancing health.

\section{Acknowledgements}

None.

\section{Conflict of interest}

Author declares that there is no conflict of interest.

\section{References}

1. Pulz O, Gross W. Valuable products from biotechnology of microalgae. Appl Microbiol Biotechnol. 2004;65(6):635-648.

2. Bahar B, O’Doherty JV, Hayes M, et al. Extracts of brown seaweeds can attenuate the bacterial lipopolysaccharide-induced pro-inflammatory response in the porcine colon ex vivo. J Anim Sci. 2012;90 Suppl 4:46-48.

3. Suhaila M, Siti NH, Hafeedza AR. Seaweeds: A sustainable functional food for complementary and alternative therapy. Trends Food Sci Tech. 2012;23(2):83-96.

4. Miyashita K. Seaweed carotenoid, fucoxanthin, with highly bioactive and nutritional activities. J Mar Bio Biotech. 2006;1:48-58.
5. Zou Y, Qian ZJ, Li Y, et al. Antioxidant effects of phlorotannins isolated from Ishigeokamurae in free radical mediated oxidative systems. J Agric Food Chem. 2008;56(16):7001-7009.

6. Gupta S, Abu-Ghannam N. Bioactive potential and possible health effects of edible brown seaweeds. Trends Food Sci Tech. 2011;22(6):315-326.

7. Michell C, Lahaye $\mathrm{M}$, Bonnet $\mathrm{C}$, et al. In vitro fermentation by human faecal bacteria of total and purified dietary fibres from brown seaweeds. Br J Nutr. 1996;75(2):263-280.

8. Vidanarachchi JK, Iji PA, Mikkelsen LL, et al. Isolation and characterization of water-soluble prebiotic com-pounds from Australian and New Zealand plants. Carbohydr Po-lym. 2009;77(3):670-676.

9. Nightingale RVD, Balasubramanian R, Anantharaman P. Antibacterial activity of seaweeds from Vellar and Uppanar estuaries, India. Ecol Environ Conserv. 2007;13(2):433-437.

10. Pesando D, Caram B. Screening of marine algae from the French Mediterranean coast for antibacterial and antifungal activity. Botanica Marina. 1984;27(8):381-386.

11. Kamenarska Z, Julia S, Hristo N, et al. Antibacterial, antiviral, and cytotoxic activities of some red and brown seaweeds from the Black Sea. Bot Mar. 2009;52(1):80-86.

12. Jaskari J, Kontula P, Siitonen A, et al. Oat b-glucan and xylanhydrolysates as selective substrates for Bifidobacterium and Lactobacillus strains. Appl Microbiol Biotechnol. 1998;49(2):175-181.

13. Deville C, Gharbi M, Dandrifosse G, et al. Study on the effects of laminarin, a polysaccharide from seaweed, on gut characteristics. $J \mathrm{Sci}$ Food Agric. 2007;87(9):1717-1725.

14. Lynch MB, Sweeney T, Callan JJ, et al. The effect of dietary Laminariaderived laminarin and fucoidan on intestinal microflora and volatile fatty acid concentration in pigs. J Sci Food Agric. 2010;90(3):430-437.

15. Rossi R, Pastorelli G, Cannata S, et al. Recent advances in the use of fatty acids as supplements in pig diets: A review. Anim Feed Sci Technol. 2010;162(1-2):1-11.

16. Shibata H, Limuro M, Uchiya $N$, et al. Preventive effects of Cladosiphonfucoidan against Helicobacter pylori in Mongolian gerbils. Helicobacter. 2003;8(1):59-65.

17. O'Doherty JV, McDonnell P, Figat S. The effect of dietary laminarin and fucoidan in the diet of the weanling piglet on performance and selected faecal microbial populations. Livestock Science. 2010;134(1-3):208-210.

18. Reilly P, Sweeney T, Pierce KM, et al. The effect of seaweed extract inclusion on gut health and immune status of the weaned pig. Animal. 2008;2(10):1465-1473.

19. Mukhopadhya A, O'Doherty JV, Smith A, et al. The microbiological and immunomodulatory effects of spray-dried versus wet dietary supplementation of seaweed extract in the pig gastrointestinal tract. $J$ Anim Sci. 2012;90(4):28-30.

20. McAlpine P, O'Shea CJ, Varley PF, et al. The effect of seaweed extract as an alternative to zinc oxide diets on growth performance, nutrient digestibility, and fecal score of weaned piglets. J Anim Sci. 2012;90(Suppl 4):224-226.

21. Gahan DA, Lynch MB, Callan JJ, et al. Performance of weanling piglets offered low, medium or high lactose diets supplemented with a seaweed extract from Laminaria spp. Animal. 2009;3(1):24-31. 
22. Walsh AM, Sweeney T, O'Shea CJ, et al. Effect of supplementing varying inclusion levels of laminarin and fucoidan on growth performance, digestibility of diet components, selected faecalmicrobial populations and volatile fatty acid concentrations in weaned pigs. Anim Feed Sci Tech. 2013;183(3-4):151-159.

23. Balboa EM, Conde E, Moure A, et al. In vitro antioxidant properties of crude extracts and compounds from brown algae. Food Chem. 2013;138(2-3):1764-1785.

24. O’Sullivan AM, O'Callaghan YC, O'Grady MN. In vitro and cellular antioxidant activities of seaweed extracts prepared from five brown seaweeds harvested in spring from the west coast of Ire-land. Food Chem. 2011;126(3):1064-1070.

25. Zhang Q, Li N, Liu X, et al. The structure of a sulfated galactan from Porphyrahaitanensis and its in vivo antioxidant activity. Carbohydr Res. 2004;339(1):105-111.

26. Michiels J, Skrivanova E, Missotten J, et al. Intact brown seaweed (Ascophyllumnodosum) in diets of weaned piglets: effects on performance, gut bacteria and morphology and plasma oxidative status. J Anim Physiol Anim Nutr (Berl). 2012;96(6):1101-1111.

27. Heo SJ, Yoon WJ, Kim KN, et al. Evaluation of anti-inflammatory effect of fucoxanthin isolated from brown algae in lipopolysaccharidestimulated RAW 264.7 macrophages. Food Chem Toxicol. 2010;48(8-9):2045-2051.
28. Sweeney T, Collins CB, Reilly P, et al. Effect of purified b-glucans derived from Laminariadigitata. Laminariahyperborea and Saccharomyces cerevisiae on piglet performance, selected bacterial populations, volatile fatty acids and pro-inflammatory cytokines in the gastrointestinal tract of pigs. Brit J Nutr. 2012;108(7):1226-1234.

29. Smith AG, O'Doherty JV, Reilly P, et al. The effects of laminarin derived from Laminariadigitata on measurements of gut health: selected bacterial populations, intestinal fermentation, mucin gene expression and cytokine gene expression in the pig. Brit J Nutr. 2011;105(5):669-677.

30. Soltanian S, Stuyven E, Cox E, et al. Beta-glucans as immunostimulant in vertebrates and invertebrates. Crit Rev Microbiol. 2009;35(2):109-138.

31. Leonard SG, Sweeney T, Bahar B, et al. The effects of maternal dietary supplementation with seaweed extract and fish oil on the humoral immune response and performance of suckling piglets. Livestock Science. 2010;134(1-3):211-214.

32. Katayama M, Fukuda T, Okamura T, et al. Effect of dietary addition of seaweed and licorice on the immune performance of pigs. Anim Sci J. 2011;82(2):274-281. 